\title{
Direct Hyperpolarization of Nitrogen-15 in Aqueous Media with Parahydrogen in Reversible Exchange
}

\author{
Johannes F. P. Colell, ${ }^{\dagger}$ Meike Emondts, ${ }^{\ddagger}$ Angus W. J. Logan, ${ }^{\dagger}$ Kun Shen, ${ }^{\dagger}$ Junu Bae, ${ }^{\dagger}$
}

Roman V. Shchepin, ${ }^{\S}$ Gerardo X. Ortiz, Jr., ${ }^{\dagger}$ Peter Spannring,,$"$ Qiu Wang, ${ }^{\dagger}{ }^{\dagger}$ Steven J. Malcolmson, ${ }^{\dagger}$ Eduard Y. Chekmenev, ${ }^{\S, \perp \odot ~ M a r t i n ~ C . ~ F e i t e r s, ~}{ }^{\|}$Floris P. J. T. Rutjes, ${ }^{\| \odot ~ B e r n h a r d ~ B l u ̈ m i c h, ~}, *$ Thomas Theis, ${ }^{*} \dagger \odot$ and Warren S. Warren ${ }^{*}, * \#$

${ }^{\dagger}$ Department of Chemistry, Duke University, Durham, North Carolina 27708, United States

${ }^{\ddagger}$ Institute for Technical and Macromolecular Chemistry, RWTH Aachen University, Worringerweg 2, 52072 Aachen, Germany

${ }^{\S}$ Departments of Radiology and Radiological Sciences, Biomedical Engineering, Physics and Astronomy, Vanderbilt Institute of Imaging Science (VUIIS), Vanderbilt Ingram Cancer Center (VICC), Vanderbilt University, Nashville, Tennessee 37232, United States

"Institute for Molecules and Materials, Radboud University, Heyendaalseweg 135, 6525 AJ Nijmegen, The Netherlands

${ }^{\perp}$ Russian Academy of Sciences, Moscow, Russia

\# Departments of Physics, Radiology and Biomedical Engineering, Duke University, Durham, North Carolina 27707, United States

Supporting Information

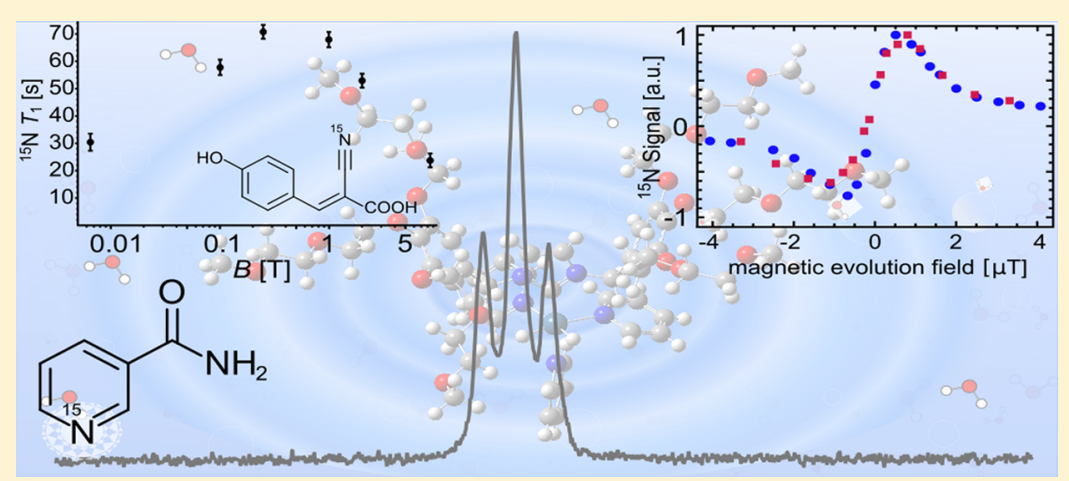

ABSTRACT: Signal amplification by reversible exchange (SABRE) is an inexpensive, fast, and even continuous hyperpolarization technique that uses para-hydrogen as hyperpolarization source. However, current SABRE faces a number of stumbling blocks for translation to biochemical and clinical settings. Difficulties include inefficient polarization in water, relatively short-lived ${ }^{1} \mathrm{H}$-polarization, and relatively limited substrate scope. Here we use a water-soluble polarization transfer catalyst to hyperpolarize nitrogen-15 in a variety of molecules with SABRE-SHEATH (SABRE in shield enables alignment transfer to heteronuclei). This strategy works in pure $\mathrm{H}_{2} \mathrm{O}$ or $\mathrm{D}_{2} \mathrm{O}$ solutions, on substrates that could not be hyperpolarized in traditional ${ }^{1} \mathrm{H}$-SABRE experiments, and we record ${ }^{15} \mathrm{~N} T_{1}$ relaxation times of up to $2 \mathrm{~min}$.

\section{INTRODUCTION}

NMR and MRI are nondestructive methods to obtain information about molecular structure and spatial morphology. However, magnetic resonance is restricted mainly by the inherently low sensitivity as a result of low thermal polarization levels. For example, NMR spectroscopy and clinical MRI predominantly use highly abundant ${ }^{1} \mathrm{H}$ nuclei. Even so, observation of low concentration analytes remains challenging. Hyperpolarization methods (e.g., DNP, PHIP, SABRE, SEOP $)^{1-7}$ enhance MR signals by $4-5$ orders of magnitude and overcome inherent sensitivity limitations. ${ }^{9-12}$

Traditionally, hyperpolarization methods require extensive optimization. Usually methods and optimization are associated with high experimental complexity and cost. In this regard, signal amplification by reversible exchange (SABRE) stands out because it is simple, fast, and continuously repeatable. ${ }^{4,13}$ SABRE uses readily available para-hydrogen $\left(p-\mathrm{H}_{2}\right)$ as a source of polarization. The transfer occurs in reversibly formed substrate-hydrogen adducts in a transition metal complex. The magnetic evolution field $B_{\text {evo }}$ must be sufficiently low to mix energy levels between hydride- ${ }^{1} \mathrm{H}$ and the target nucleus to establish a path for polarization transfer. ${ }^{7,14}$ While protons in the substrate are targeted at magnetic fields around $65 \mathrm{G},{ }^{15}$ transfer to heteronuclei (e.g., ${ }^{15} \mathrm{~N},{ }^{13} \mathrm{C},{ }^{31} \mathrm{P}$ ) occurs at $\mu \mathrm{T}$ magnetic fields using a technique termed SABRE in shield

Received: January 17, 2017

Published: April 26, 2017 
enables alignment transfer to heteronuclei (SABRESHEATH) ${ }^{7,8}$ As shown in Scheme 1, the required hardware is relatively simple.

Scheme 1. A sample is hyperpolarized via SABRE-SHEATH for an evolution time $t_{\text {evo }}$ at optimized matching field $B_{\text {evo }}$ of $\sim 0.5 \mu \mathrm{T}$ established by a small solenoid coil in a magnetic shield that attenuates the Earth's magnetic field and transferred into a Benchtop (1 T) NMR spectrometer or conventional high-field $(8.45 \mathrm{~T})$ spectrometer for detection.

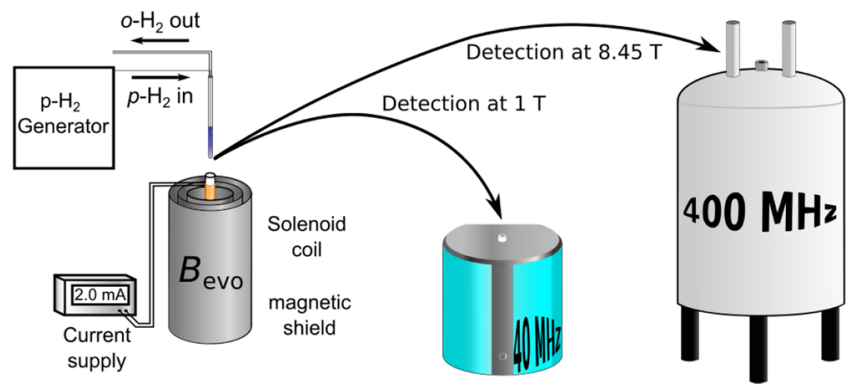

As a result of experimental simplicity and its promise, SABRE and SABRE-SHEATH are now attracting an increasing number of research groups contributing to its rapid development. ${ }^{4,7,15-21}$ A milestone for SABRE was the transition from organic solvents to aqueous solutions, which was recently achieved for ${ }^{1} \mathrm{H}$-SABRE. ${ }^{22-28}$

Still, for ${ }^{1} \mathrm{H}$ spin-lattice relaxation times are relatively short and the substrate scope is limited. Direct polarization transfer to heteronuclei has not been demonstrated in an aqueous environment. Hyperpolarizing nitrogen-15 via SABRESHEATH allows a wider range of structural motifs, and relaxation times are characteristically larger.

SABRE-SHEATH with ${ }^{15} \mathrm{~N}$ targets is made accessible with the water-soluble $[\operatorname{IrCl}(\mathrm{IDEG})(\mathrm{COD})]$ precatalyst (1a). As shown in Scheme 2 the precatalyst is converted to the catalytically active species (1) in the presence of substrates under a hydrogen atmosphere. ${ }^{22}$ At $\mu \mathrm{T}$ magnetic field hydride and ${ }^{15} \mathrm{~N}$ energy levels match and the spin system coherently evolves with a rate given by $J_{\mathrm{NH}^{-}}$into ${ }^{15} \mathrm{~N}$-polarization on substrates. $^{29}$

We investigate different molecular motifs found in medical drugs, biomolecules, and molecular tags. Structural motifs could be readily translated from the established [ $\mathrm{IrCl}(\mathrm{IMes})(\mathrm{COD})]$ system. ${ }^{16,30}$

Pyridine (2), the canonical SABRE substrate, ${ }^{4}$ was a logical first choice. Next, nitriles are often encountered in drugs, ${ }^{31}$ polarize consistently well, tolerate complex backbones, and show large ${ }^{15} \mathrm{~N}$-SABRE-SHEATH enhancements, despite little to no ${ }^{1} \mathrm{H}$-SABRE enhancements. ${ }^{30,32}$ We selected benzonitrile (3) and $\alpha$-cyano-4-hydroxycinnamic acid (4) (CHCA, buffered with $\mathrm{NaOD}$ to $\mathrm{pH} 7.5$ ). Diazirines, which also do not exhibit ${ }^{1} \mathrm{H}$ enhancements, are common biomolecular tags that can replace $\mathrm{CH}_{2}$ groups in many classes of biomolecules. ${ }^{33}$ Here we use 2-cyano-3-( $\left(D_{3}\right.$-methyl- ${ }^{15} \mathrm{~N}_{2}$-diazirine)propanoic acid (5). Lastly, we focus on nicotinamide (6), the amide of vitamin $B_{3}$, which could be tolerated in vivo at detectable concentrations $s^{34-36}$ and is a potential option for translation to biomedical studies. $^{20,37}$

For these substrates we detail hyperpolarization levels, carefully characterize temperature and magnetic field dependencies, consider the effect of deuterated vs protonated solvents
Scheme 2. Precatalyst [IrCl(IDEG)(COD)] (1a) is transformed into the active species $\left[\operatorname{Ir}(\mathrm{IDEG})(\mathrm{H})_{2} \mathrm{Sub}_{3}\right]$ $(\mathrm{Sub}=$ Substrate $)(1)$ in presence of a substrate of choice (2-6) under a hydrogen atmosphere; reversible exchange leads to polarization buildup on ${ }^{15} \mathrm{~N}$ within $30-120 \mathrm{~s}$; the polarization transfer is primarily driven by the $\mathrm{N}-\mathrm{H}$ coupling through the bonds that form a $180^{\circ}$ angle as the $\mathrm{N}-\mathrm{H}$ coupling through bonds forming a $90^{\circ}$ angle is close to zero.

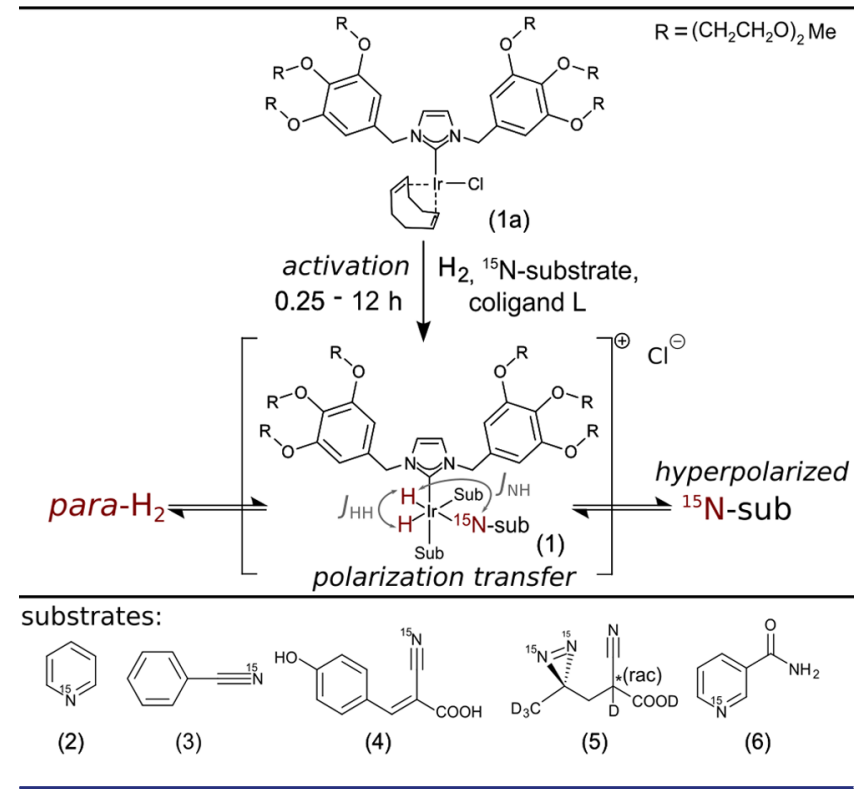

$\left(\mathrm{D}_{2} \mathrm{O}\right.$ vs $\left.\mathrm{H}_{2} \mathrm{O}\right)$, and measure relaxation time constants at various magnetic fields.

\section{RESULTS AND DISCUSSION}

In Figure 1 we show a comparison between single-scan spectra originating from compounds directly SABRE-SHEATH hyperpolarized in aqueous medium, referenced to thermally polarized neat ${ }^{15} \mathrm{~N}$-pyridine at $8.45 \mathrm{~T}$. Concentrations of investigated compounds are different as a result of solubility as well as sample loss phenomena for benzonitrile and pyridine. Both pyridine and benzonitrile were initially prepared as $100 \mathrm{mM}$ solutions, but after activation by $\mathrm{H}_{2}$ bubbling the concentrations were significantly reduced.

A synopsis of experimental results and conditions is given in Table 1 (experimental details provided in Materials and Methods). Spectra are acquired at $1 \mathrm{~T}$ and $8.45 \mathrm{~T}$ (see Scheme 1) to study the field dependence of $T_{1}$ relaxation as detailed below. The $1 \mathrm{~T}$ measurements also demonstrate the feasibility of high-sensitivity single-scan ${ }^{15} \mathrm{~N}$ detection with a benchtop NMR system. Furthermore, to determine the effect of proton-containing solvents, nicotinamide was investigated in $\mathrm{H}_{2} \mathrm{O}$.

We find that polarization levels in deuterated solvents are largely independent of the detection field; that is, enhancements simply scale with the thermal polarization. In contrast, for nicotinamide in $\mathrm{H}_{2} \mathrm{O}$ (Table 1 , entry 6), we observe lower apparent polarization levels at $8.45 \mathrm{~T}$. This is caused by relaxation losses during transfer because it takes much longer to transfer the sample into the high-field magnet $(\sim 8 \mathrm{~s})$ than into the benchtop device sitting right next to the magnetic shields ( $\sim 2 s)$. The solvent protons (and deuterons) are in chemical exchange with the ${ }^{15} \mathrm{~N}$-substrate, where they cause spin-dipole 

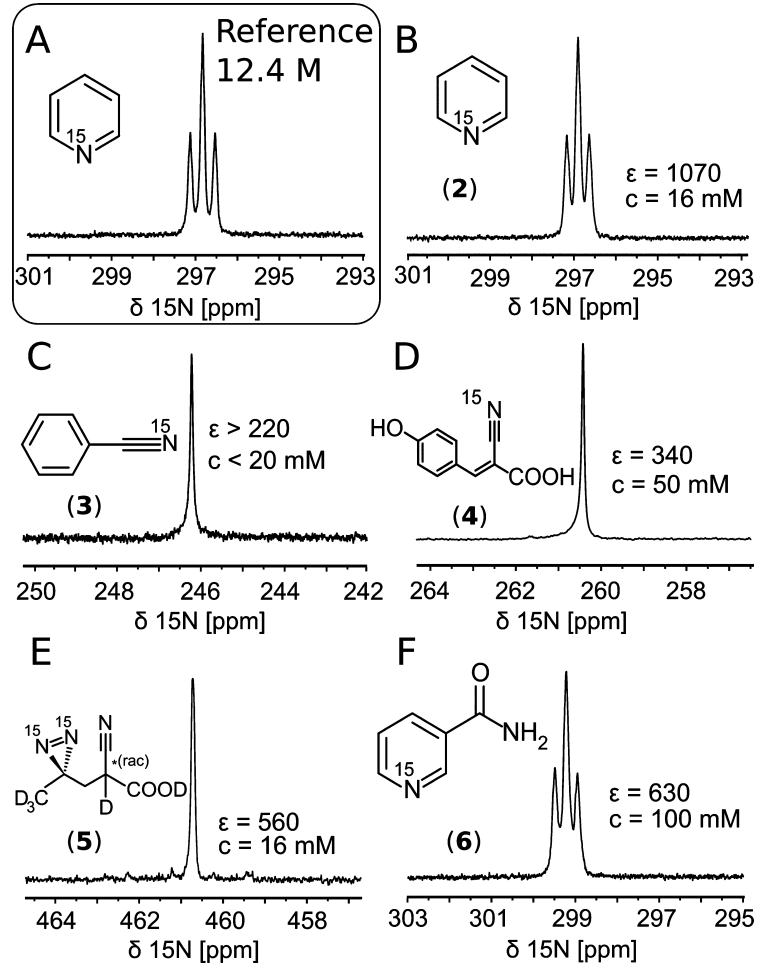

Figure $1 .{ }^{15} \mathrm{~N}$ spectra of $(\mathrm{A})$ thermally polarized reference at $8.45 \mathrm{~T}$ and $\left(\mathrm{B}-\mathrm{F}\right.$ ) hyperpolarized compounds (in $\mathrm{D}_{2} \mathrm{O}$ unless denoted otherwise). (A) Neat ${ }^{15} \mathrm{~N}$-pyridine, (B) ${ }^{15} \mathrm{~N}$-pyridine, (C) ${ }^{15} \mathrm{~N}$ benzonitrile, (D) ${ }^{15} \mathrm{~N}$-CHCA, (E) ${ }^{15} \mathrm{~N}_{2}$-diazirine, (F) ${ }^{15} \mathrm{~N}$-nicotinamide (in $\mathrm{H}_{2} \mathrm{O}$ ).

relaxation. This relaxation mechanism scales with the distance between the relaxation partners $r_{i j}^{-6}$ as well as the gyromagnetic ratio, which is 6.5 times smaller for deuterium, ${ }^{38,39}$ explaining the observed differences between solvents.

SABRE-SHEATH in water gives rise to a new set of challenges. Water has significantly higher viscosity and surface tension than methanol, and at room temperature the solubility of hydrogen in water is 5 times lower. ${ }^{40,41}$ We observed that some samples, specifically nonpolar liquid-state substrates (e.g., benzonitrile and pyridine), are extracted from the solvent when bubbling with hydrogen during the polarization buildup. Nicotinamide and CHCA, both crystalline solids when isolated, were used for systematic studies, as substrate loss did not occur. $^{20}$

Of particular interest are the dependence of the ${ }^{15} \mathrm{~N}$ polarization on temperature and magnetic evolution field $B_{\text {evo }}$. Figure 2 contrasts the established $[\operatorname{IrCl}(\mathrm{IMes})(\mathrm{COD})]$ in methanol and catalyst $\mathbf{1}$ in $\mathrm{H}_{2} \mathrm{O} / \mathrm{D}_{2} \mathrm{O}$ as a function of these variables $\left(T, B_{\text {evo }}\right)$.
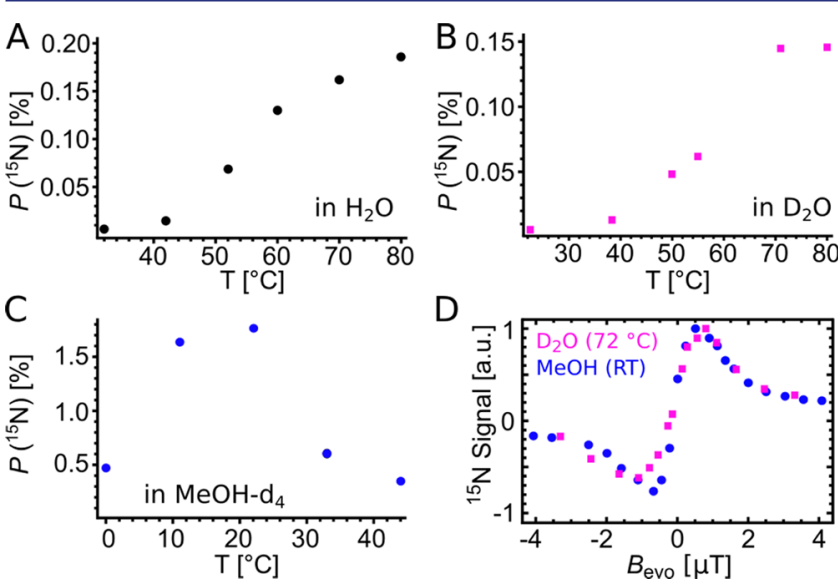

$\mathrm{D}$

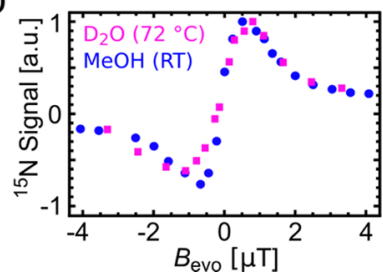

Figure 2. Comparison of ${ }^{15} \mathrm{~N}$ polarization as a function of temperature in (A) $\mathrm{H}_{2} \mathrm{O}$, (B) $\mathrm{D}_{2} \mathrm{O}$, and (C) methanol- $d_{4}$ at $B_{\text {evo }}=0.5 \mu \mathrm{T}$. (D) Hyperpolarized signals as a function of $\mu \mathrm{T}$ field at the temperature corresponding to the maximum polarization in the respective solvents: $22{ }^{\circ} \mathrm{C}$ for ${ }^{15} \mathrm{~N}$-acetonitrile in methanol- $d_{4}$ and $72{ }^{\circ} \mathrm{C}$ for ${ }^{15} \mathrm{~N}-\mathrm{CHCA}$ in $\mathrm{D}_{2} \mathrm{O}$ (blue: $5 \mathrm{mM}$ [ $\left.\mathrm{IrCl}(\mathrm{IMes})(\mathrm{COD})\right], 30 \mathrm{mM}$ pyridine, $100 \mathrm{mM}$ ${ }^{15} \mathrm{~N}-\mathrm{CH}_{3} \mathrm{CN}$, methanol- $d_{4}$; magenta: $5 \mathrm{mM}$ [IrCl(IDEG)(COD)], 30 $\mathrm{mM}$ pyridine, $50 \mathrm{mM}{ }^{15} \mathrm{~N}-\mathrm{CHCA}, \mathrm{D}_{2} \mathrm{O}$ ).

The temperature dependence was studied using a $100 \mathrm{mM}$ nicotinamide sample. For catalyst system $\mathbf{1}$ in $\mathrm{H}_{2} \mathrm{O}$ (Figure 2A) and $\mathrm{D}_{2} \mathrm{O}$ (Figure $2 \mathrm{~B}$ ) the ${ }^{15} \mathrm{~N}$ polarization increases with temperature. In contrast, in methanol (Figure 2C, $[\mathrm{IrCl}(\mathrm{IMes})$ (COD)] precursor) the largest polarization is recorded at room temperature.

The magnetic field dependence is shown in Figure 2D. We compare normalized data (max. ${ }^{15} \mathrm{~N}$ polarization: $0.13 \%$ in $\mathrm{D}_{2} \mathrm{O}, 1.7 \%$ in $\left.\mathrm{MeOH}-d_{4}\right)$ of two nitrile/solvent systems: first, in blue, ${ }^{15} \mathrm{~N}$-acetonitrile in $\mathrm{MeOH}-d_{4}$ with [ $\left.\operatorname{IrCl}(\mathrm{IMes})(\mathrm{COD})\right]$ and second, in magenta, ${ }^{15} \mathrm{~N}-\mathrm{CHCA}$ in $\mathrm{D}_{2} \mathrm{O}$ with [IrCl$(\mathrm{IDEG})(\mathrm{COD})]$ (1a).

We note that nitriles are better suited for this study than nicotinamide, as enhancements are more robust and reproducible. Additionally, they exhibit inversion of the NMR signal upon inversion of $B_{\text {evo }}$. Variation of the temperature changes the dissociation rate constants of substrate and catalyst-bound $\mathrm{H}_{2} \cdot{ }^{14,16,42}$ Optimal polarization transfer efficiency is expected when the exchange rate $k_{\text {diss }}$ is on the order of the ${ }^{15} \mathrm{~N}$ to hydride $J_{\mathrm{NH}^{-}}$-coupling across the iridium center (see Scheme 2). ${ }^{14,42}$ Figure $1 \mathrm{~A}-\mathrm{C}$ show that the IMes catalyst in methanol yields the largest ${ }^{15} \mathrm{~N}$ polarization at room temperature,

Table 1. Synopsis of Experimental Conditions, Enhancements, and Polarization Levels ${ }^{a}$

\begin{tabular}{|c|c|c|c|c|c|c|}
\hline substrate & $\begin{array}{c}\text { activation time } \\
{[\mathrm{h}]}\end{array}$ & $\begin{array}{c}c_{\text {substrate }} / \\
c_{\text {catalyst }}\end{array}$ & $\begin{array}{l}c_{\text {Substrate }} \\
{[\mathrm{mM}]}\end{array}$ & $\begin{array}{c}\text { enhancement } 8.45 \mathrm{~T}(P \\
[\%])\end{array}$ & $\begin{array}{c}\text { enhancement } 1 \mathrm{~T}(P \\
[\%])\end{array}$ & $\begin{array}{c}\text { enhancement ratio }(1 \mathrm{~T} / \\
8.45 \mathrm{~T})\end{array}$ \\
\hline (2) pyridine & 12 & 3.3 & $16.5^{c}$ & 1100 & $d$ & $d$ \\
\hline (3) benzonitrile & 0.25 & 20 & $50^{b, c}$ & 90 & $d$ & $d$ \\
\hline (4) $\mathrm{CHCA}$ & 12 & 10 & 50 & $440(0.13)$ & $3700(0.13)$ & 8.4 \\
\hline (5) diazirine & 6 & 10 & 16.3 & $560(0.16)$ & $4700(0.17)$ & 8.4 \\
\hline (6) nicotinamide & 12 & 20 & 100 & $520(0.16)$ & $6100(0.21)$ & 8.9 \\
\hline (6) nicotinamide $\mathrm{H}_{2} \mathrm{O}$ & 12 & 20 & 100 & $630(0.2)$ & $10500(0.37)$ & 28 \\
\hline
\end{tabular}

${ }^{a}$ Substrates are ${ }^{15} \mathrm{~N}$ labeled, solvent is $\mathrm{D}_{2} \mathrm{O}$ unless otherwise specified. Concentrations of liquid substrates are determined at the time of the experiment using ${ }^{1} \mathrm{H}$ spectroscopy. $T=75^{\circ} \mathrm{C}$. ${ }^{b}$ Signal maximum obtained $30 \mathrm{~min}$ after activation, subsequent substrate loss due to evaporation. ${ }^{c}$ Initial concentration $100 \mathrm{mM}$. ${ }^{d}$ Insufficient $\mathrm{S} / \mathrm{N}$ ratio. 
whereas catalyst 1 requires significantly elevated temperatures to achieve comparable exchange rates leading to maximum polarization. On the basis of these insights it is reasonable to expect ${ }^{15} \mathrm{~N}$ polarization in water to decrease at even higher temperatures, in analogy to methanol, as shown in Figure 2C.

As seen in Figure 2D, the methanol and water systems show very similar responses to $B_{\text {evo }}$ at their respective optimized temperatures $\left(22\right.$ and $\left.72{ }^{\circ} \mathrm{C}\right)$. The response curves originate from two distinct matching conditions associated with overpopulation in ${ }^{15} \mathrm{~N}-\alpha$ or ${ }^{15} \mathrm{~N}-\beta$, giving either positive or negative NMR signal with identical polarization levels. ${ }^{30}$ The matching conditions are given $b^{7}$

$$
B_{\text {evo }}= \pm \frac{J_{\mathrm{HH}}+J_{\mathrm{NH}} / 2}{\gamma_{\mathrm{H}}-\gamma_{\mathrm{N}}}
$$

where $J_{\mathrm{HH}}$ is the hydride to hydride $J$-coupling $(\sim 10 \mathrm{~Hz})$ and $J_{\mathrm{NH}}$ the hydride to ${ }^{15} \mathrm{~N}$ coupling $(\sim 20 \mathrm{~Hz})$ in 1. Experimentally, we observe maxima at $B_{\text {evo }} \approx \pm 0.5 \mu \mathrm{T}$, which is slightly higher than the $\pm 0.3 \mu \mathrm{T}$ predicted from eq 1 , as the limited lifetime broadens the matching conditions.

Taken together, the observations of Figure 1A-D suggest that the activation energy of substrate dissociation from 1 is significantly larger than for the established [ $\operatorname{IrCl}(\mathrm{IMes})$ (COD)]-methanol systems. This is also supported by the fact that catalyst $\mathbf{1}$ in methanol at RT did not yield any enhancement.

The absolute polarization level in $\mathrm{D}_{2} \mathrm{O}$ is about one order of magnitude smaller than for the methanol system, when compared at their respective optimized temperatures $\left({ }^{15} \mathrm{~N}\right.$ CHCA in $\mathrm{D}_{2} \mathrm{O}, P\left({ }^{15} \mathrm{~N}\right)=0.13 \%,{ }^{15} \mathrm{~N}-\mathrm{CH}_{3} \mathrm{CN}$ in $d_{4}-\mathrm{MeOH}$, $\left.P\left({ }^{15} \mathrm{~N}\right)=1.7 \%\right)$. Interestingly, this difference in hyperpolarization level can simply be attributed to the difference in hydrogen solubility (factor 5) and the difference in solvent concentration $\left(c\left(\mathrm{H}_{2} \mathrm{O}\right)=55 \mathrm{~mol} / \mathrm{L}, c(\mathrm{MeOH})=28 \mathrm{~mol} / \mathrm{L}\right.$, factor 2).

Current experimental data and theoretical considerations indicate that SABRE polarization levels are limited by the exchange of hydrides on the iridium center and the exchange kinetics of other ligand types (substrate/solvent), as well as both pressure and flow rate of para-hydrogen. Exchange of hydrogen restores the polarization source to the active complex species and the process proceeds via the mixed classical/ nonclassical hydride $\left[\operatorname{Ir}(\mathrm{H})_{2}\left(\eta-\mathrm{H}_{2}\right)(\mathrm{IMes}) \mathrm{L}_{2}\right]$, with arbitrary ligands L. ${ }^{14,16}$ Formation of this species requires collision between a 16-electron complex and a hydrogen molecule, where collision with a para-hydrogen molecule may refresh the active species. As a result, the polarization is proportional to the concentration of para-hydrogen in solution, not the saturation concentration of hydrogen (ortho + para). Accordingly, the pressure dependence of polarizations is relatively weak, whereas dependence on the flow rate is significant. Depending on system composition, a linear or exponential dependence of ${ }^{15} \mathrm{~N}$ polarization on the flow rate was reported..$^{30,43,44}$ We conclude that the para-hydrogen enrichment in solution is limited by the exchange at the gas-liquid interface.

Let us now consider the substrate exchange process. The rates of ligand dissociation $k_{\text {diss }}$ and association $k_{\text {asso }}$ determine not only the lifetime of the complex, where polarization transfer from the hydrides to the target nuclei occurs, but also the concentration of the 16-electron species required for the hydride exchange. ${ }^{14}$ As a result ${ }^{15} \mathrm{~N}$ polarization depends directly on the concentration of the 16-electron species.
Accordingly, the largest polarizations are observed at relatively low catalyst concentrations and high catalyst loadings. It is noteworthy that an exponential dependence of polarization on the substrate concentrations has been observed by Appleby et al. $^{45}$

We point out that all reported polarization levels are not optimized with respect to sample composition, concentrations, hydrogen pressure, or flow rate. Optimization of catalyst concentration and loading afforded an 8-10-fold increase of ${ }^{15} \mathrm{~N}$ polarization level for the methanol system. Maximum polarizations are recorded at low catalyst concentrations and high catalyst loadings $\left({ }^{15} \mathrm{~N}\right.$-nicotinamide $P\left({ }^{15} \mathrm{~N}\right)=7 \%$, ${ }^{15} \mathrm{~N}$-benzonitrile $P\left({ }^{15} \mathrm{~N}\right)=16 \%$, metronidazole at natural abundance $\left.P\left({ }^{15} \mathrm{~N}\right)=20 \%\right) \cdot{ }^{7,14,18,43,46}$ We conclude that ${ }^{15} \mathrm{~N}$ polarization can be increased by at least a factor 10 by using low substrate concentrations and high catalyst loading. Further improvements are expected by modifications to the experimental setup to allow for more effective mixing of hydrogen and solvent at higher pressures.

${ }^{15} \mathrm{~N}$ Relaxation Times in Water. Of particular importance for hyperpolarization applications is the spin-lattice relaxation time $T_{1}$, which defines the viable time delay between preparation of hyperpolarization and detection. We examined the $T_{1}$ lifetime for ${ }^{15} \mathrm{~N}$-nicotinamide ${ }^{46}$ and ${ }^{15} \mathrm{~N}-\mathrm{CHCA}$, which constitute biocompatible compounds and contain ${ }^{15} \mathrm{~N}$ in chemically different environments. ${ }^{46-48}$ Table 2 shows the ${ }^{15} \mathrm{~N} T_{1}$ relaxation times in $\mathrm{D}_{2} \mathrm{O}$, which at $1 \mathrm{~T}$ exceed $1 \mathrm{~min}$ for both compounds.

Table 2. ${ }^{15} \mathrm{~N} T_{1}$ Times of $100 \mathrm{mM}$ Nicotinamide and $50 \mathrm{mM}$ CHCA in $\mathrm{D}_{2} \mathrm{O}$ at Different Detection Fields

$\begin{array}{lrc} & T_{1}[\mathrm{~s}] 1 \mathrm{~T} & T_{1}[\mathrm{~s}] 8.45 \mathrm{~T} \\ { }^{15} \mathrm{~N}-\mathrm{CHCA} & 71 \pm 15^{a} & 24 \pm 3 \\ { }^{15} \mathrm{~N} \text {-nicotinamide } & 116 \pm 10 & 32^{b} \pm 4\end{array}$

${ }^{a}$ Detected and stored at $1 \mathrm{~T}$. Control by detection at $8.45 \mathrm{~T}: T_{1}=68$ \pm 2 s. ${ }^{b} \mathrm{In} \mathrm{H}_{2} \mathrm{O}: 32 \pm 5.5$ s.

For ${ }^{15} \mathrm{~N}$-nicotinamide at $8.45 \mathrm{~T}$ we find the effect of protoncontaining solvent $\left(\mathrm{H}_{2} \mathrm{O}\right)$ on the $T_{1}$ time to be negligible. It should be noted that the ${ }^{15} \mathrm{~N} T_{1}$ time of nicotinamide at $8.45 \mathrm{~T}$ and room temperature is close to the $T_{1}$ reported for ${ }^{13} \mathrm{C}$ in the ${ }^{13} \mathrm{C}(1)$-pyruvate markers currently in clinical use for prostate cancer diagnostics $\left(T_{1}=29.2 \mathrm{~s}\right.$ in vivo, $T_{1}=60 \mathrm{~s}$, ex vivo, $3 \mathrm{~T}){ }^{9,10}$ It is noteworthy that the ${ }^{13} \mathrm{C} T_{1}$ values in vivo are smaller than those ex vivo, characteristic for diffusion in constricted environments.

To elucidate this field dependence in more detail, we hyperpolarized ${ }^{15} \mathrm{~N}-\mathrm{CHCA}$ and held the sample at different fields for variable times prior to detection. The results are shown in Figure 3, displaying ${ }^{15} \mathrm{~N}$-relaxation time of $\mathrm{CHCA}$ $\left(50 \mathrm{mM}, \mathrm{pH} 7.5, \mathrm{D}_{2} \mathrm{O}\right)$ at different magnetic fields. For this compound relatively low magnetic fields of about $0.2 \mathrm{~T}$ give the longest relaxation times. This is an intriguing finding in the context of low-field approaches to NMR and MRI, ${ }^{49}, 30$ which could be coupled with SABRE to establish low-cost spectroscopy and molecular imaging.

The scaling of signal-to-noise with magnetic field strongly depends on the exact experimental conditions. For traditional thermal NMR, the signal is proportional to polarization and the induction. Both terms are proportional to $B_{0}$; thus the signal scales with $B_{0}{ }^{2} \cdot{ }^{38,51}$ In NMR, coil noise is typically dominant, 


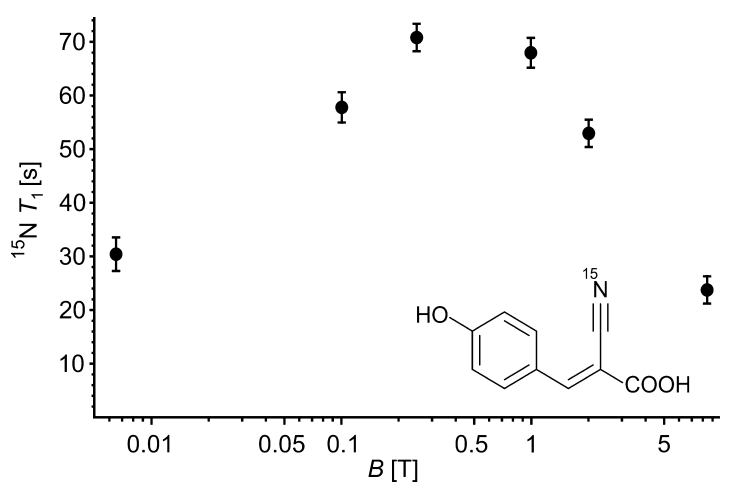

Figure 3. ${ }^{15} \mathrm{~N} T_{1}$ time constant of CHCA as a function of the magnetic field. The sample is hyperpolarized and stored at a given field for an incremented delay time and detected at $8.45 \mathrm{~T}$.

which scales as $B_{0}{ }^{1 / 4}$; hence signal-to-noise $(\mathrm{S} / \mathrm{N})$ is proportional to $B_{0}^{7 / 4}$. $^{-53}$ However, with a hyperpolarized sample spin polarization is independent of $B_{0}$ and, thus, $S / N$ scales with $B_{0}^{3 / 4}$.

Another scenario arises for human MRI. Here, dielectric losses dominate, which are proportional to $B_{0}$. Thus, $\mathrm{S} / \mathrm{N}$ only increases proportional to $B_{0}$ for thermal MRI experiments. ${ }^{52,54}$ Therefore, $\mathrm{S} / \mathrm{N}$ is expected to be independent of $B_{0}$ for hyperpolarized human MRI. ${ }^{55,56}$ MRI in low magnetic fields has significant advantages, as magnet and RF-circuit design are flexible, easy to construct, and relatively inexpensive. ${ }^{56,87}$ For example, high-performance ${ }^{1} \mathrm{H}-\mathrm{MRI}$ at $6.5 \mathrm{mT}$ with thermal magnetization has already been reported. ${ }^{49}$ It is noteworthy that recent advances in the low-field domain, such as "external high-quality-factor-enhanced NMR" (EHQE-NMR) ${ }^{58}$ and others, ${ }^{59}$ lead to $\mathrm{S} / \mathrm{N}$ independent of $B_{0}$ even for spectroscopic applications.

\section{MATERIALS AND METHODS}

Solutions of substrates in $\mathrm{D}_{2} \mathrm{O} / \mathrm{H}_{2} \mathrm{O}$ were added to $[\mathrm{IrCl}(\mathrm{IDEG})$ (COD)] (IDEG = 1,3-bis(3,4,5-tris (diethyleneglycol)benzyl) $)$-imidazole-2-ylidene), $\mathrm{COD}=1,5$-cyclooctadiene), stirred until a homogeneous solution of known concentration in catalyst is obtained, and transferred to a $5 \mathrm{~mm}$ medium wall pressure NMR tube (Wilmad 524PV-7). The typical sample volume was $350 \mu \mathrm{L}$. The solution was bubbled with argon for $30 \mathrm{~min}$ and pressurized with $10 \mathrm{bar}$ of para $-\mathrm{H}_{2}$, and hydrogen flow was adjusted to obtain adequate bubbling. Catalyst activation times were $0.25-12 \mathrm{~h}$ depending on substrate, solvent (deuterated solvents require longer activation times), and temperature. Catalyst activation can be sped up significantly by raising the temperature. For SABRE-SHEATH experiments para- $\mathrm{H}_{2}$ (Bruker BPHG 090, $38 \mathrm{~K}, 90 \%$ ) was bubbled through a sample placed in a $\mu \mathrm{T}$ magnetic field. Hyperpolarization buildup is achieved in $0.5-2 \mathrm{~min}$. The $\mu \mathrm{T}$ field is generated by a small solenoid inside a magnetic shield (see Scheme 1). The sample temperature was controlled with a water bath inside the magnetic shields. Measurements were performed with a Bruker Avance DX $360(8.45 \mathrm{~T})$ or Magritek Spinsolve ${ }^{1} \mathrm{H} /{ }^{15} \mathrm{~N}$ spectrometer $(1 \mathrm{~T})$. Enhancements are calculated relative to neat ${ }^{15} \mathrm{~N}$ labeled pyridine. The concentration in the samples was monitored by ${ }^{1} \mathrm{H}$ spectroscopy.

\section{CONCLUSIONS}

We have demonstrated SABRE-SHEATH hyperpolarization of ${ }^{15} \mathrm{~N}$ in aqueous media at moderate temperatures $\left(20-80{ }^{\circ} \mathrm{C}\right)$ and achieve up to 1000 -fold enhancements over thermal measurements at $8.45 \mathrm{~T}$. We applied SABRE-SHEATH in water to biocompatible marker groups in different molecules (CHCA, nicotinamide, diazirine moieties). Hyperpolarization of ${ }^{15} \mathrm{~N}$-nitrile and the ${ }^{15} \mathrm{~N}_{2}$-diazirine exemplifies how SABRESHEATH is amenable to more substrate classes because ${ }^{15} \mathrm{~N}$ is closer to the hyperpolarization source than protons in the molecular backbone.

Furthermore, we demonstrated $T_{1}$ times comparable to, or exceeding, clinically used DNP tracers. ${ }^{9,10}$ For example, nicotinamide in $\mathrm{D}_{2} \mathrm{O}$ exhibits a ${ }^{15} \mathrm{~N}$ relaxation time of 2 min, which is significantly longer than typical ${ }^{1} \mathrm{H}-T_{1}$ (seconds) of traditional ${ }^{1} \mathrm{H}$-SABRE substrates. Still, recent advances have demonstrated long-lived ${ }^{1} \mathrm{H}$ singlet states with decay times of up to $4.5 \mathrm{~min} .{ }^{37}$ When such strategies are translated to ${ }^{15} \mathrm{~N}$, lifetimes in excess of 20 min become available. ${ }^{60}$

Imaging applications of SABRE hyperpolarized protons ${ }^{25}$ as well as nitrogen-15 have already been reported. ${ }^{43}$ Hyperpolarized heteronuclei are beneficial, as they are background free and have a large chemical shift range, which allows for easy chemical identification. Future developments may be expected to advance SABRE to in vivo molecular imaging complementing DNP-hyperpolarized ${ }^{13} \mathrm{C}$ tracers, which have quickly become an essential and routine tool, giving detailed and fundamental insight into in vivo metabolism and biochemistry. ${ }^{9,10,61-65}$

\section{ASSOCIATED CONTENT}

\section{S Supporting Information}

The Supporting Information is available free of charge on the ACS Publications website at DOI: 10.1021 /jacs.7b00569.

Relaxation time measurements, detailed description of experimental procedures, spectral data, physicochemical reference data for $\mathrm{H}_{2} \mathrm{O}$ (PDF)

\section{AUTHOR INFORMATION}

\section{Corresponding Authors}

*bluemich@itmc.rwth-aachen.de

*thomas.theis@duke.edu

*warren.warren@duke.edu

ORCID $\odot$

Johannes F. P. Colell: 0000-0001-9020-344X Qiu Wang: 0000-0002-6803-9556

Steven J. Malcolmson: 0000-0003-3229-0949

Eduard Y. Chekmenev: 0000-0002-8745-8801

Floris P. J. T. Rutjes: 0000-0003-1538-3852

Thomas Theis: 0000-0001-6779-9978

Notes

The authors declare no competing financial interest.

\section{ACKNOWLEDGMENTS}

The authors gratefully acknowledge the NSF (CHE-1363008 and CHE-1416268), NIH 1R21EB018014, P41 EB015897 and 1R21EB020323, DOD CDMRP W81XWH-15-1-0271 and W81XWH-12-1-0159/BC112431, and Duke University for financial support of this research. This work has been supported by Deutsche Forschungsgemeinschaft (DFG-BL231/47-1), as well as by the European Union and the provinces of Gelderland and Overijssel (NL) through the EFRO Ultrasense NMR project. The authors gratefully acknowledge Magritek for supply of the $1 \mathrm{~T}^{15} \mathrm{~N}$-spectrometer and friendly technical assistance.

\section{REFERENCES}

(1) Carver, T. R.; Slichter, C. P. Phys. Rev. 1956, 102, 975-980. 
(2) Cudalbu, C.; Comment, A.; Kurdzesau, F.; van Heeswijk, R. B.; Uffmann, K.; Jannin, S.; Denisov, V.; Kirik, D.; Gruetter, R. Phys. Chem. Chem. Phys. 2010, 12, 5818-5823.

(3) Shchepin, R. V.; Coffey, A. M.; Waddell, K. W.; Chekmenev, E. Y. Anal. Chem. 2014, 86, 5601-5605.

(4) Adams, R. W.; Aguilar, J. A.; Atkinson, K. D.; Cowley, M. J.; Elliott, P. I. P.; Duckett, S. B.; Green, G. G. R.; Khazal, I. G.; LopezSerrano, J.; Williamson, D. C. Science 2009, 323, 1708-1711.

(5) Bowers, C. R.; Weitekamp, D. P. Phys. Rev. Lett. 1986, 57, 26452648.

(6) Ben-Amar Baranga, A.; Appelt, S.; Romalis, M. V.; Erickson, C. J.; Young, A. R.; Cates, G. D.; Happer, W. Phys. Rev. Lett. 1998, 80, 2801-2804.

(7) Theis, T.; Truong, M. L.; Coffey, A. M.; Shchepin, R. V.; Waddell, K. W.; Shi, F.; Goodson, B. M.; Warren, W. S.; Chekmenev, E. Y. J. Am. Chem. Soc. 2015, 137, 1404-1407.

(8) Barskiy, D. A.; Shchepin, R. V.; Tanner, C.; Colell, J. F. P.; Goodson, B. M.; Theis, T.; Warren, W. S.; Chekmenev, E. Y. ChemPhysChem 2017, DOI: 10.1002/cphc.201700416.

(9) Kurhanewicz, J.; Vigneron, D. B.; Brindle, K.; Chekmenev, E. Y.; Comment, A.; Cunningham, C. H.; DeBerardinis, R. J.; Green, G. G.; Leach, M. O.; Rajan, S. S.; Rizi, R. R.; Ross, B. D.; Warren, W. S.; Malloy, C. R. Neoplasia 2011, 13, 81-97.

(10) Nelson, S. J.; Kurhanewicz, J.; Vigneron, D. B.; Larson, P. E. Z.; Harzstark, A. L.; Ferrone, M.; van Criekinge, M.; Chang, J. W.; Bok, R.; Park, I.; Reed, G.; Carvajal, L.; Small, E. J.; Munster, P.; Weinberg, V. K.; Ardenkjaer-Larsen, J. H.; Chen, A. P.; Hurd, R. E.; Odegardstuen, L. I.; Robb, F. J.; Tropp, J.; Murray, J. A. Sci. Transl. Med. 2013, 5, 198ra108-198ra108.

(11) Eshuis, N.; van Weerdenburg, B. J. A.; Feiters, M. C.; Rutjes, F. P. J. T.; Wijmenga, S. S.; Tessari, M. Angew. Chem., Int. Ed. 2015, 54, $1372-1372$.

(12) Eshuis, N.; Hermkens, N.; van Weerdenburg, B. J. A.; Feiters, M. C.; Rutjes, F. P. J. T.; Wijmenga, S. S.; Tessari, M. J. Am. Chem. Soc. 2014, 136, 2695-2698.

(13) Hövener, J.-B.; Schwaderlapp, N.; Lickert, T.; Duckett, S. B.; Mewis, R. E.; Highton, L. A. R.; Kenny, S. M.; Green, G. G. R.; Leibfritz, D.; Korvink, J. G.; Hennig, J.; von Elverfeldt, D. Nat. Commun. 2013, 4, 2946.

(14) Barskiy, D. A.; Pravdivtsev, A. N.; Ivanov, K. L.; Kovtunov, K. V.; Koptyug, I. V. Phys. Chem. Chem. Phys. 2015, 89, 89-93.

(15) Zeng, H.; Xu, J.; Gillen, J.; McMahon, M. T.; Artemov, D.; Tyburn, J.-M.; Lohman, J. A. B.; Mewis, R. E.; Atkinson, K. D.; Green, G. G. R.; Duckett, S. B.; van Zijl, P. C. M. J. Magn. Reson. 2013, 237, $73-78$.

(16) Cowley, M. J.; Adams, R. W.; Atkinson, K. D.; Cockett, M. C. R.; Duckett, S. B.; Green, G. G. R.; Lohman, J. A. B.; Kerssebaum, R.; Kilgour, D.; Mewis, R. E. J. Am. Chem. Soc. 2011, 133, 6134-6137.

(17) Theis, T.; Truong, M.; Coffey, A. M.; Chekmenev, E. Y.; Warren, W. S. J. Magn. Reson. 2014, 248, 23-26.

(18) Barskiy, D. A.; Shchepin, R. V.; Coffey, A. M.; Theis, T.; Warren, W. S.; Goodson, B. M.; Chekmenev, E. Y. J. Am. Chem. Soc. 2016, 138, 8080-8083.

(19) Nikolaou, P.; Goodson, B. M.; Chekmenev, E. Y. Chem. - Eur. J. 2015, 21, 3156-3166.

(20) Shchepin, R. V.; Barskiy, D. A.; Coffey, A. M.; Theis, T.; Shi, F.; Warren, W. S.; Goodson, B. M.; Chekmenev, E. Y. ACS Sensors 2016, $1,640-644$

(21) Shchepin, R. V.; Chekmenev, E. Y. J. Labelled Compd. Radiopharm. 2014, 57, 621-624.

(22) Spannring, P.; Reile, I.; Emondts, M.; Schleker, P. P. M.; Hermkens, N. K. J.; van der Zwaluw, N. G. J.; van Weerdenburg, B. J. A.; Tinnemans, P.; Tessari, M.; Blümich, B.; Rutjes, F. P. J. T.; Feiters, M. C. Chem. - Eur. J. 2016, 22, 9277-9282.

(23) Truong, M. L.; Shi, F.; He, P.; Yuan, B.; Plunkett, K. N.; Coffey, A. M.; Shchepin, R. V.; Barskiy, D. A.; Kovtunov, K. V.; Koptyug, I. V.; Waddell, K. W.; Goodson, B. M.; Chekmenev, E. Y. J. Phys. Chem. B 2014, 18, 13882-13889.
(24) Fekete, M.; Bayfield, O.; Duckett, S. B.; Hart, S.; Mewis, R. E.; Pridmore, N.; Rayner, P. J.; Whitwood, A. Inorg. Chem. 2013, 52, 13453-13461.

(25) Rovedo, P.; Knecht, S.; Bäumlisberger, T.; Cremer, A. L.; Duckett, S. B.; Mewis, R. E.; Green, G. G. R.; Burns, M. J.; Rayner, P. J.; Leibfritz, D.; Korvink, J. G.; Hennig, J.; Pütz, G.; von Elverfeldt, D.; Hövener, J.-B. J. Phys. Chem. B 2016, 120, 5670-5677.

(26) Hövener, J.-B.; Schwaderlapp, N.; Borowiak, R.; Lickert, T.; Duckett, S. B.; Mewis, R. E.; Adams, R. W.; Burns, M. J.; Highton, L. A. R.; Green, G. G. R.; Olaru, A.; Hennig, J.; von Elverfeldt, D. Anal. Chem. 2014, 86, 1767-1774.

(27) Zeng, H.; Xu, J.; McMahon, M. T.; Lohman, J. A. B.; van Zijl, P. C. M. J. Magn. Reson. 2014, 246, 119-121.

(28) Shi, F.; He, P.; Best, Q. A.; Groome, K.; Truong, M. L.; Coffey, A. M.; Zimay, G.; Shchepin, R. V.; Waddell, K. W.; Chekmenev, E. Y.; Goodson, B. M. J. Phys. Chem. C 2016, 120, 12149-12156.

(29) Barskiy, D. A.; Pravdivtsev, A. N.; Ivanov, K. L.; Kovtunov, K. V.; Koptyug, I. V. Phys. Chem. Chem. Phys. 2015, 18, 89-93.

(30) Colell, J. F. P.; Logan, A. W. J.; Zhou, Z.; Shchepin, R. V.; Barskiy, D. A.; Ortiz, G. X.; Wang, Q.; Malcolmson, S. J.; Chekmenev, E. Y.; Warren, W. S.; Theis, T. J. Phys. Chem. C 2017, 121, 6626.

(31) Fleming, F. F.; Yao, L.; Ravikumar, P. C.; Funk, L.; Shook, B. C. J. Med. Chem. 2010, 53, 7902-7917.

(32) Mewis, R. E.; Green, R. A.; Cockett, M. C. R.; Cowley, M. J.; Duckett, S. B.; Green, G. G. R.; John, R. O.; Rayner, P. J.; Williamson, D. C. J. Phys. Chem. B 2015, 119, 1416-1424.

(33) Dubinsky, L.; Krom, B. P.; Meijler, M. M. Bioorg. Med. Chem. 2012, 20, 554-570.

(34) Bergmann, F.; Wislicki, L. Br. J. Pharmacol. Chemother. 1953, 8, $49-53$.

(35) Guyton, J. R.; Blazing, M. A.; Hagar, J.; Kashyap, M. L.; Knopp, R. H.; McKenney, J. M.; Nash, D. T.; Nash, S. D. Arch. Intern. Med. 2000, 160, 1177-1184.

(36) Libri, V.; Yandim, C.; Athanasopoulos, S.; Loyse, N.; Natisvili, T.; Law, P. P.; Chan, P. K.; Mohammad, T.; Mauri, M.; Tam, K. T.; Leiper, J.; Piper, S.; Ramesh, A.; Parkinson, M. H.; Huson, L.; Giunti, P.; Festenstein, R. Lancet 2014, 384, 504-513.

(37) Roy, S. S.; Norcott, P.; Rayner, P. J.; Green, G. G. R.; Duckett, S. B. Angew. Chem., Int. Ed. 2016, 55, 15642-15645.

(38) Abragam, A. The Principles of Nuclear Magnetism; Clarendon Press: Oxford, 1961.

(39) Halbach, K. Nucl. Instrum. Methods 1980, 169, 1-10.

(40) Crozier, T. E.; Yamamoto, S. J. Chem. Eng. Data 1974, 19, $242-$ 244.

(41) Brunner, E. J. Chem. Eng. Data 1985, 30, 269-273.

(42) Knecht, S.; Pravdivtsev, A. N.; Hövener, J.-B.; Yurkovskaya, A. V.; Ivanov, K. L. RSC Adv. 2016, 6, 24470-24477.

(43) Truong, M. L.; Theis, T.; Coffey, A. M.; Shchepin, R. V.; Waddell, K. W.; Shi, F.; Goodson, B. M.; Warren, W. S.; Chekmenev, E. Y. J. Phys. Chem. C 2015, 119, 8786-8797.

(44) Shchepin, R. V.; Truong, M. L.; Theis, T.; Coffey, A. M.; Shi, F.; Waddell, K. W.; Warren, W. S.; Goodson, B. M.; Chekmenev, E. Y. J. Phys. Chem. Lett. 2015, 6, 1961-1967.

(45) Appleby, K. M.; Mewis, R. E.; Olaru, A. M.; Green, G. G. R.; Fairlamb, I. J. S.; Duckett, S. B. Chem. Sci. 2015, 6, 3981-3993.

(46) Shchepin, R. V.; Barskiy, D. A.; Mikhaylov, D. M.; Chekmenev, E. Y. Bioconjugate Chem. 2016, 27, 878-882.

(47) Wang, H.; Lanks, K. W. Cancer Res. 1986, 46, 5349-5352.

(48) Olaru, A. M.; Burns, M. J.; Green, G. G. R.; Duckett, S. B. Chem. Sci. 2016, 8, 2257-2266.

(49) Sarracanie, M.; LaPierre, C. D.; Salameh, N.; Waddington, D. E. J.; Witzel, T.; Rosen, M. S. Sci. Rep. 2015, 5, 15177.

(50) Danieli, E.; Mauler, J.; Perlo, J.; Blümich, B.; Casanova, F. J. Magn. Reson. 2009, 198, 80-87.

(51) Hoult, D. I.; Richards, R. E. J. Magn. Reson. 1976, 24, 71-85.

(52) Hoult, D. I.; Lauterbur, P. C. J. Magn. Reson. 1979, 34, 425-433.

(53) Hoult, D. I. Sensitivity of the NMR Experiment. In eMagRes.; John Wiley \& Sons, Ltd, 2007. 
(54) Hoult, D. I. Enc. Magn. Reson. 2007, DOI: 10.1002/ 9780470034590.emrstm0491.

(55) Hoult, D. I.; Richards, R. E. J. Magn. Reson. 1976, 24, 71-85.

(56) Minard, K. R.; Wind, R. A. Concepts Magn. Reson. 2001, 13, 190-210.

(57) Danieli, E.; Perlo, J.; Blümich, B.; Casanova, F. Phys. Rev. Lett. 2013, 110, 180801-1-5.

(58) Suefke, M.; Liebisch, A.; Blumich, B.; Appelt, S. Nat. Phys. 2015, 11, 767-771.

(59) Coffey, A. M.; Truong, M.; Chekmenev, E. Y. J. Magn. Reson. 2013, 237, 169-174.

(60) Theis, T.; Ortiz, G. X.; Logan, A. W. J.; Claytor, K. E.; Feng, Y.; Huhn, W. P.; Blum, V.; Malcolmson, S. J.; Chekmenev, E. Y.; Wang, Q.; Warren, W. S. Sci. Adv. 2016, 2, e1501438-e1501438.

(61) Nelson, S. J.; Kurhanewicz, J.; Vigneron, D. B.; Larson, P. E.; Harzstark, A. L.; Ferrone, M.; van Criekinge, M.; Chang, J. W.; Bok, R.; Park, I.; Reed, G.; Carvajal, L.; Small, E. J.; Munster, P.; Weinberg, V. K.; Ardenkjaer-Larsen, J. H.; Chen, A. P.; Hurd, R. E.; Odegardstuen, L. I.; Robb, F. J.; Tropp, J.; Murray, J. A. Sci. Transl. Med. 2013, 5, 198ra108.

(62) Sriram, R.; Van Criekinge, M.; Hansen, A.; Wang, Z. J.; Vigneron, D. B.; Wilson, D. M.; Keshari, K. R.; Kurhanewicz, J. NMR Biomed. 2015, 28, 1141-1149.

(63) Keshari, K. R.; Sriram, R.; Van Criekinge, M.; Wilson, D. M.; Wang, Z. J.; Vigneron, D. B.; Peehl, D. M.; Kurhanewicz, J. Prostate 2013, 73, 1171-1181.

(64) Rodrigues, T. B.; Serrao, E. M.; Kennedy, B. W. C.; Hu, D.-E.; Kettunen, M. I.; Brindle, K. M. Nat. Med. 2013, 20, 93-97.

(65) Reile, I.; Eshuis, N.; Hermkens, N. K. J.; van Weerdenburg, B. J. A.; Feiters, M. C.; Rutjes, F. P. J. T.; Tessari, M. Analyst 2016, 141, 4001-4005. 